\title{
Cancer Chemosensitivity Testing: Review
}

\author{
Yongzhuang $\mathrm{Su}^{*}$ \\ Cerritos, USA \\ Email:yzsu@hotmail.com
}

Received 17 April 2014; revised 15 May 2014; accepted 22 May 2014

Copyright (C) 2014 by author and Scientific Research Publishing Inc. This work is licensed under the Creative Commons Attribution International License (CC BY). http://creativecommons.org/licenses/by/4.0/ (c) (i) Open Access

\begin{abstract}
Since chemotherapy started in 1940s, chemosensitivity testing has been both a very attractive field and one fraught with potential pitfalls. Many methods were developed and brought initial promises, yet later ending in disappointment and were eliminated. For example, in the 1970s clonogenic assay was generally believed to be the best testing method for predicting clinical outcome. However, technical problems including low evaluation rate limited its use. Currently, MTT, ATP, DISC and Kern's assay hold better promises. Since the 90s, the study of molecular biology has been progressing rapidly. It accelerated the understanding of molecular mechanisms of drug response. Numerous papers were published, but only few techniques can be applied in clinical practice. This review summarizes the controversies and current progress of chemosensitivity assays based on available online information, and makes a suggestion about their future routine practice.
\end{abstract}

\section{Keywords}

\section{Cancer, Chemosensitivity Testing, Cell Culture, Molecular}

\section{Background}

Chemotherapy is one of the main therapies for cancer patient, even useful for the patient at the end of life [1]. However, its severe toxicity and uncertain effects often led to failure. Chemotherapy is believed to provide benefit to only $30 \%-70 \%$ of patients. The chemosensitivity testing has been a longstanding object for several decades. Despite a great deal of efforts, real progress has been limited and their effectiveness is under constant debate.

Chemosensitivity advocates believe testing can help physicians choose the active drug and regimen for individual patient to enhance patient's response and avoid unnecessary toxicities.

For example, in a study of patients with non small cell lung cancer who received pre-surgical adjuvant chemotherapy, with the aid of assessing the chemosensitivity of the tumor, permits the early withdrawal of treatment if it fails (presently in $40 \%$ of patients) [2]. Numerous studies demonstrated the correlation between in vi-

*Active member of AACR since 1989, retired. 
tro testing result and in vivo outcome [3]. Chemosensitivity testing is not only useful for tailoring therapy, but also useful for screening new therapeutic agents and regimen, hastening the introduction of new drugs and reducing cost [4].

However, there exist some opposing opinions in this field:

1) Extreme heterogeneity of cellular, molecular and drug sensitivity in tumor. It causes the timing and spacing differences of response, such as between the patients with same pathological diagnosis, naive and relapse cancer, original and metastatic cancer [5], different metastatic organs. For example, hepatic metastatic tumor is more resistant than lymph node metastatic tumor [6], even cells from different site in the same tumor shown different sensitivity to drug [7].

2) Microenvironment difference between in vivo and in vitro. The condition of in vivo is different from that in vitro cell culture, which is without immune environment and lack of normal cell such as macrophage, lymphocytes [8]. Similar to infection tests, even though in vitro condition is not the same as in vivo condition, the test result still can be as a good reference.

3) The retrospective trial and the prospective trial. Up to now most trials are retrospective. When the positive results accumulate to a certain level, they will be primed for prospective trial. At that time, actual use in clinical practice could be available in the near future.

4) Toxicity of drugs on tumor versus normal cells. As standard practice, the assay only tests the effect of drug on tumor cells, not including the effect on normal tissues. If the toxicity of a drug on normal cells is as strong as that on tumor cells, it would not be meaningful to choose it for the patient [9]? The therapeutic index is usually measured when screening a new drug, whereas the toxicity of drug to individual patient is estimated by other tests.

5) Cost-efficiency. Currently, the assays cost range from $\$ 1000$ to $\$ 4000$, which is argued by some as cost prohibitive. However, chemotherapy and immunotherapy are far more expensive, while cost and effectiveness of both can be optimized with tailored treatment from the results of the chemosensitivity study. When this testing becomes routine, the economy of scale would lower the cost per test, improving the chance of its coverage by health insurance.

\section{Progress of Chemosensitivity Testing}

In interest of a clearer explanation, chemosensitivity testings are classified into three groups as below. Each has its strong points, and supplements each other. Histoculture drug response assays (HDRA) examine the overall effects of drugs for viability, proliferation, metabolism of tumor cells, also offer cells for molecular study. Molecular biologic study probes into the mechanisms of drug action, for example, the status of some biomarkers such as targeted molecule can precisely predict clinical outcome, but it often uses the result of HDRA as a criterion. In vivo testing is useful for clinical outcome follow up, but thus far its usage is limited to certain diseases and sometimes it is not sensitive enough.

\subsection{In Vitro Histoculture Drug Response Assay (HDRA)}

These methods use fresh samples from patients, after separation and purification, and prepared as cell suspension. The samples are exposed with drugs in microculture plates for 2 - 4 days, then they are examined to determine the effects of drugs on tumor cells to predict the clinical outcome. Presently, MTT, ATP, DISC, Kern and clonogenic assay are more common methods.

Kern assay (an isotope-labeled precursors incorporation inhibition assay) [10] and clonogenic assay [11] detect the effects of drug on the proliferation cells.

ATP and MTT are widely used for the last 20 years. Both assays are simple, sensitive, robust, and adaptable techniques and used in hematological and solid tumors. Their results from many laboratories have shown to be accurate in predicting clinical outcomes, so they can be used for tailoring chemotherapy [12] [13]. Cree I.A. reported a prospective clinical trail in patients with ovarian cancer. Anticancer agents selected individually by ATP assay have been found to triple the response rate and nearly double the survival rate compared to empirical chosen regimens. The accurate rate of prediction sensitivity is $85 \%$ - $90 \%$, for resistance is $100 \%$. ATP assay is considered as the best predictive testing method [14]. Sargent J.M. used MTT assay for patients with ovarian or AML for 12 years. They found the correlation rate between in vitro test and clinical outcome is 98\% for AML, and 81\% for ovarian cancer respectively [15]. Both ATP and MTT assay are also used for new drug screenings. Their disadvantage is that benign cells also show reactions. When the non-malignant cell population is over $20 \%$ 
of total cell population, it will interfere with the end results. In that situation, DISC assay is a better choice. DISC assay (differential staining cytotoxicity assay) can discriminate between malignant and contaminate nonmalignant cells, dead cells and living cells based on morphologic criteria. A numerous publications have demonstrated the clinical value of this assay [16] [17]. The major drawbacks are its very labor-intensive, requires skilled technicians to read slides using a microscope, and the results are subject to individual interpretations. Only when the manual processes of this assay can be automated with robotics and computerized data analysis, will it then be widely accepted and used by other laboratories. Besides, MTT, ATP and DISC assay predict the effect of cytotoxic agents while for cytostatic agents including most molecular therapeutic agents, they only can detect synergestic effect with other cytotoxic agent, and are not suitable for predicting the effect of single agent. Moreover, they detect short time effect on cell kill and metabolism, while for detecting the effect on proliferation in longer time, clonogenic assay still holds more promise.

There are some newer assays such as MICK microculture kinetic assay of apoptosis [18] and the ChemoFx assay [19]. There are few reports on them, therefore they are not discussed here.

\subsection{Molecular Biological Thechniques}

Since the 1990s, molecular biology has progresses at an incredible rate. A number of microarray-based techniques have been applicable to the study of chemosensitivity. Technigues such as SNP (single nucleotide polymorphism), SEP (serial gene profiling) gene and miRNA expression profiling, high/low density throughput sequencing, mutation analysis, ctDNA or DNA methylation, signaling pathway regulation analysis, siRNA, shRNA dsRNA screening by special quantitative PCR, chromosome imbalance study and analysis of protein by immunohistochemitry. Now large scale data can be analyzed by computational methods with high efficiency [20]. These new techniques accelerate the study of structure and function of protein, DNA, RNA in cancer cells, and are used in predicting drug response.

Molecular study of predicting chemosensitivity includes:

1) Molecular pathology

Predicting drug response based on molecular pathological diagnosis. Thus far, studies have been focused on following tumors and reported similar results (Table 1).

Table 1. Molecular characteristics and clinical significance in different cancer.

\begin{tabular}{|c|c|c|c|}
\hline Cancer & Biomarker study & Significance & Reference \\
\hline $\mathbf{O A}$ & Loss of chromosome $1 p$ and $19 q$ & Sensitive to chemotherapy and better prognosis & {$[21][22]$} \\
\hline \multirow{4}{*}{ NSCLC } & ERCC1/MDR1 SNP & Associated with sensitivity to platinum & {$[23]$} \\
\hline & DNA mehtylation and repair & Predict chemosensitivity & {$[24]-[26]$} \\
\hline & Kappa B & Predict chemosensitivity & {$[27]$} \\
\hline & Deletion of chromosome 11p15 & Resistance to gemcitabine & {$[27]$} \\
\hline \multirow{4}{*}{ Brest } & HER-2 & Poorer prognosis & [28] \\
\hline & BRCA 1 mutation & Conflict results of chemosensitivity & [29] \\
\hline & P53 mutation & Drug resistance & [29] \\
\hline & TNBC & Sensitive to chemotherapy and biological therapy & [30] \\
\hline Stomach & Oncogene, antioncogenes, DNA repair, receptors, & Diagnosis and predict chemosensitivity & {$[31][32]$} \\
\hline Skin & DNA microarray & Diagnosis and predict chemosensitivity & {$[33]$} \\
\hline PETs & $\begin{array}{l}\text { Loss of heterogosity, alterations of oncogenes, } \\
\text { antioncogenes, growth factors and receptors }\end{array}$ & $\begin{array}{l}\text { Prognostic significance } \\
\text { Targetable gene and protein }\end{array}$ & {$[34]$} \\
\hline Head and neck & $\begin{array}{l}\text { EGFR } \\
\text { P53 gene and protein }\end{array}$ & $\begin{array}{l}\text { Prognosis } \\
\text { Predict clinical outcome }\end{array}$ & [35] \\
\hline AML & $\begin{array}{l}\text { Microarray combine with } \\
\text { flow cytometry }\end{array}$ & $\begin{array}{l}\text { Predict chemosensitivity, diagnostic and } \\
\text { pharmacokinetic study }\end{array}$ & [36] \\
\hline OVA & CA-125 change & Predict the treatment outcome & {$[37]$} \\
\hline $\mathbf{O A}$ & Oligodendroglioma & & \\
\hline TNBC & Triple negative breast cancer & & \\
\hline PETs & Pancreactic endocrine tumors & & \\
\hline
\end{tabular}


Molecular pathology can be extremely complicated, for example, sarcoma comprises more than 50 different types at the genetic, proteomic and epigenetic levels, each may have different chemosensitivities [38]. Furthermore, the results from different method or studies are hardly comparable, sometimes are conflict.

2) Pharmacogenomics

Pharmacogenomics is the molecular basis for pharmacokinetics and pharmacodynamics. It may be used in predict the clinical outcome and prognosis in the near future [39]-[41].

a) Drug resistance is one of the major reason of chemotherapy failure, therefore, received the greatest attention. One important mechanism of MDR (multiple drug resistance) involves the multidrug transporter p-glycoprotein [42]. P-gp belongs to the ATP-binding cassette (ABC) family. A number of studies have demonstrated there are 7 groups (A-G) 49 types of ABC transporters. Some may cause drug resistance by pumping drugs out of cells and thus reducing their cytotoxicity [43] [44]. Molecular basis of individual drug resistance were demonstrated, for example, resistant to cisplatin is related to DNA damaged repair; resistance to microtubuline interactive drugs taxane is associated with tubuline mutation, while resistance to gemcitabine is related to chromosomal delections of 11p 15.5, and mutation of p53 may involve in the mechanism of resistance to cisplatin and $5 \mathrm{FU}$ [45].

b) Drug metabolism. Kubata T. introduced an enzyme DPD (dihydropyrimidine dehydrogenase) assay to predict the sensitivity of gastric cancer specimen to 5-Fu. He reported that low activity of DPD and DPD mRNA is related to low sensitivity to $5 \mathrm{Fu}$ [46]. Mitomycin C (MMC) requires metabolic activation by cellular reductase for activity. The enzyme NAD (P)H:Quino Oxidoreductase-1 (NQ01) can reduce MMC to damaging species. However, attempts to establish the relationship between tumor response to MMC and NQ01 expression have generated conflicting reports of good and poor correlations. This suggests that the mechanism of action of MMC is too complex to allow tumor response to be predicted on the basis of a single enzyme. Assays should be developed that reflect the overall biological and pharmacological processes. This is also a common challenge for the molecular biological methods [47].

3) Others

a) Proteins/various inhibitors, antigens and enzymes. Detection of a universal marker—ornithin decarboxylase (ODC), may predict chemosensitivity of cancer cells [48].

b) DNA/various genes. Aberrant methylation of circulating DNA is used as predictor of the chemosensitivity of non small lung cancer [15].

c) RNA/RNAi (miRNAs and siRNAs). Circulating microRNAs are potential new biomarker for prostate cancer detection [49].

The molecular biologic testing faces two challenges: firstly, the mechanism of drug action is too complicated to predict tumor response by a single assay (see the MMC lesson above), secondly, molecular biomarkers (protein, DNA/gene, and RNA/RNAi) are always in dynamic mutation process and their interrelation is very complex. For example, there are cooperation and antagonism among cancer genes [50]. MicroRNAs (miRs) are involved in regulation of gene expressions in various signaling pathways, while miRs' activity is regulated by circular RNA [51]. They are just parts of regulation network.

Blood sample can be used to monitor circulating tumor cells (CTC), blood cells, and various molecular biomarkers such as ctDNA (circulating tumor DNA), RNA, mRNA, miRs, proteins. CTC can be used for molecular assays, cell culture and xenotransplantation assay [52]. Sato H. et al. used the NLR (neutrophil to lymphocyte ratio) to predict chemosensitivity of thoracic esophageal cancer [53]. Using peripheral blood sample is convenient, less invasive and repeatable. Furthermore, because CTC and circulating molecules released from tumors located at different site, using blood sample can exclude intrapatient heterogeneity. However, usually CTC are at low concentration and mixed with normal cells, thus requiring extremely sensitive and specific method.

\subsection{In Vivo Predicting Response Method}

Imaging analysis and flow cytometry for predicting drug response are very attractive due to being convenient, noninvasive and repeatable, especially for solid tumors. Weber WA reviewed the usage of PET (positron emission tomography) in study the pharmacokinetics of anticancer drugs and providing various markers to assess tumor response [54]. Herrmann K. et al. reviewed the methodology of PET/CT (computed tomography) for monitoring of cancer treatment [55]. Flow cytometric assay can be used as a chemosensitivity test for selecting effective anticancer drugs [56] and also for monitoring the expression of drug resistance markers [57]. 
Nude mice transplantation [58] and subrenal capsule assay [59] are rarely used in clinical practice, so not discussed here.

\section{Future Direction}

As science continues to progress, current chemosensitivity testing methods will continually be replaced by newer ones. Thus far, no methods are widely accepted by the medical society. A flawless method that can be used for all types of tumors and various drugs may never be found. However, a series of reliable methods for different type of tumor and different patient including naive or relapse can be established. These methods need to be sensitive, rapid, accurate, and repeatable. Other criteria include being reproducible, robust, simple and affordable. Because of the complexity of tumor cell and molecules, developing the chemosensitivity testing will require large research efforts and large available funding. It is not an endeavor that most laboratories can accomplish independently. This further emphasizes the need to improve collaboration and focus on productive clinical application.

\section{Suggestion:}

1) Set up a national organization for professionals with different background in oncology, pathology, cell biology, molecular biology, and bioinformatics. This organization will be in charge of rigorously examining the technique and experiences from different laboratories including universities and private entities, in order to design standardized methods periodically. For in vitro cell culture assay, the following details should be rigorously tracked regarding the specimen collection, tumor cell separation and purification, anticancer drugs preparation, concentration and exposure time, condition of cell culture, result analysis and score. This will require a sizable database, accumulating information from many laboratories. This comprehensive data can be studied to standardize methodologies and analyze results.

By collecting information on the molecular determinants (i.e., DNA, RNA or protein) gleaned from molecular biological study, we can build up a library, which will be useful for tailored chemotherapy.

2) Multi-institutional cooperation. Currently, independent laboratories perform in vitro histoculture testing and basic molecular biological analysis. Due to the prohibitive cost, newer or more complicated technologies are researched at institutional laboratories. Hospitals are mainly responsible for imaging analysis such as CT, PET tests, while bio-tech companies can offer custom-made chip or microarrays. These various entities will benefit greatly from improved cooperation with each other. Working together, the results can be clinically verified, bringing concrete progress to the field.

3) Personalized testing. Tailoring therapy for specific patient may require a combination of different methods. Personalized testing is selected by the following factors: patient's information: (age, sex, diagnosis, history of disease and treatment, liver and kidney function, and general health status), treatment plan and sample type. For example, for a patient with breast cancer, the expression of HER2/erb-B2 should be tested in order to decide whether or not use targeted therapy with transtuzumab [60]. If there are several drugs to choose, select an assay based upon the treatment plan. For example, if cDDP-based or TAXEL-based chemotherapy is selected, testing on DNA repair and the mutation of tubuline to assess the resistence to cDDP and TAXEL, then decide to use either cDDP-based or Texane-based therapy. Fresh specimen can be used for in vitro culture, flow cytometry study or biological analysis, while pathological slides are only used $\mathrm{f}$ or some biological analysis.

\section{References}

[1] Kao, S., et al. (2009) Use of Chemotherapy at End of Life in Oncology Patients. Annals of Oncology, 20, $1555-1559$. http://dx.doi.org/10.1093/annonc/mdp027

[2] Depierre, A. (2004) Pre and Perisurgical Chemotherapy of Stage I and II Resectable Non-Small Cell Lung Cancers. Revue de Pneumologie Clinique, 60, 31-36. http://dx.doi.org/10.1016/S0761-8417(04)72129-X

[3] Weisenthal, L.M. (2006) Current Status of Cell Culture Drug Resistance Testing. http://weisenthal.org/oncol-ithm

[4] Blumenthal, R.D. and Goldenberg, D. (2007) Methods and Goals for the Use of in Vitro and in Vivo Chemosensitivity Testing. Molecular Biotechnology, 35, 185-197. http://dx.doi.org/10.1007/BF02686104

[5] Kern, D.H., et al. (1984) Comparison of Drug Sensitivity among Tumor Cells within a Tumor between Primary and Metastases, and between Different Metastases in the Human Tumor Colony-Forming Assay. Cancer Research, 44, 2309-2312.

[6] Ichiyoshi, Y., Endo, K., Yamamoto, M., Maehara, Y. and Sugimachi, K. (1995) Biological Features Determining the 
Chemosensitivity of Gastric Cancer. Human Cell, 8, 157-161.

[7] Von Hoff, D.D., Clark, G.M., et al. (1986) Simultaneous in Vitro Drug Sensitivity Testing on Tumors from Different Sites in the Same Tumor. Cancer, 58, 1007-1013. http://dx.doi.org/10.1002/1097-0142(19860901)58:5<1007::AID-CNCR2820580503>3.0.CO;2-\#

[8] Phillips, R.M., Bibby, M.C. and Double, J.A. (1990) A Critical Appraisal of Predictive Value of in Vitro Chemosensitivity Assays. JNCI, 82, 1457-1468. http://dx.doi.org/10.1093/jnci/82.18.1457

[9] Wu, P.H., et al. (2006) Editorial. Challenges of Chemosensitivity Testing. Clinical Cancer Research, 12, 5258. http://dx.doi.org/10.1158/1078-0432.CCR-06-1656

[10] Kern, D.H., et al. (1984) Clinical Correlations with Chemosensitivities Measured in a Rapid Thymidine Incorporation Assay. Cancer Research, 44, 1725-1728.

[11] Bertelsen, C.A., Sondak, V.K., Mann, B.D., Korn, E.L. and Kern, D.H. (1984) Chemosensitivity Testing of Human Solid Tumors. A Review of 1582 Assays with 258 Clinical Correlations. Cancer, 53, 1240-1245. http://dx.doi.org/10.1002/1097-0142(19840315)53:6<1240::AID-CNCR2820530604>3.0.CO;2-Y

[12] Kurbacher, C.M., Grecu, O.M., Stier, U., Gilster, T.J., Janát, M.M., Untch, M., Konecny, G., Bruckner, H.W. and Cree, I.A. (2003) ATP Chempsensitivity Testing in Ovarian and Breast Cancer: Early Clinical Trial. Recent Results in Cancer Research, 161, 221-230. http://dx.doi.org/10.1007/978-3-642-19022-3_17

[13] Hayon, T., et al. (2003) Appraisal of the MTT-Based Assay as a Useful Tool for Predicting Drug Chemosensitivity in Leukemia. Leukemia \& Lymphoma, 44, 1957-1962. http://dx.doi.org/10.1080/1042819031000116607

[14] Cree, I.A. (2005) Chemosensitivity Testing Using Microplate Adenosine Triphosphate-Based Luminescence Measurements. Methods in Molecular Medicine, 110, 101-120.

[15] Sargent, J.M. (2003) The Use of the MTT Assay to Study Drug Resistance in Fresh Tumor Samples. Recent Results in Cancer Research, 161, 13-25. http://dx.doi.org/10.1007/978-3-642-19022-3_2

[16] Weisenthal, L.M. (2011) Differential Staining Cytotoxicity Assay: A Review. Methods in Molecular Biology, 731, 259-283. http://dx.doi.org/10.1007/978-1-61779-080-5 22

[17] Kaspers, G.J. (2005) Use of the Differential Staining Cytotoxicity Assay to Predict Chemosensitivity. Methods in Molecular Medicine, 110, 49-57.

[18] Kravisov, V.D., Greer, J.P., Whitlock, J.A. and Koury, M.J. (1998) Use of Microculture Kinetic Assay of Apoptosis in Determine Chemosensitivities of Leukemias. Blood, 92, 968-980.

[19] Brower, S.L., Fensterer, J.E. and Bush, J.E. (2008) The ChemoFx Assay: An ex Vivo Chemosensitivity and Resistance Assay for Predicting Patient Response to Cancer Chemotherapy. Methods in Molecular Biology, 414, 57-78.

[20] Masica, D.L. and Karchin, R. (2013) Collections of Simultaneously Altered Genes as Biomarkers of Cancer Cell Drug Response. Cancer Research, 73, 1699-1708. http://dx.doi.org/10.1158/0008-5472.CAN-12-3122

[21] Fontaine, D., Vandenbos, F., Lebrun, C., Paquis, V. and Frenay, M. (2008) Diagnostic and Prognostic Values of 1p and 19q Deletions in Adult Gliomas: Critical Review of the Literature and Implications in Daily Clinical Practice. Revue Neurologique (Paris), 164, 595-604. http://dx.doi.org/10.1016/j.neurol.2008.04.002

[22] Li, S., Yan, C., Huang, L., Qiu, X., Wang, Z. and Jiang, T. (2012) Molecular Prognostic Factors of Anaplastic Oligodendroglial Tumors and Its Relationship: A Single Institutional Review of 77 Patients from China. Neuro-Oncology, 14, 109-116. http://dx.doi.org/10.1093/neuonc/nor185

[23] Wei, H.B., Hu, J., Shang, L.H., Zhang, Y.Y., Lu, F.F., Wei, M., et al. (2012) A Meta-Analytic Review of ERCC1/ MDR1 Polymorphism and Chemosensitivity to Platinum in Patients with Advanced Non-Small Cell Lung Cancer. Chinese Medical Journal (English), 125, 2902-2907.

[24] Takai, D. (2010) Aberrant Methylation of Circulating DNA for Predicting of Chemosensitivity of Non-Small Cell Lung Cancer. Gan to Kagaku Ryoho, 37, 189-193.

[25] Oda, S., Kuraoka, I. and Maehara Y. (2007) DNA Repair as a Determinant of Tumor Chemosensitivity. Gan to Kagaku Ryoho, 34, 347-357.

[26] García-Campelo, R., Alonso-Curbera, G., Aparicio, L.M.A. and Rosell, R. (2005) Pharmacogenomics in Lung Cancer: An Analysis of DNA Repair Gene Expression in Patients Treated with Platinum-Based Chemotherapy. Expert Opinion on Pharmacotherapy, 6, 2015-2026. http://dx.doi.org/10.1517/14656566.6.12.2015

[27] Rosell, R., Tarón, M. and O’Brate, A. (2001) Predictive Molecular Markers in Non-Small Cell Lung Cancer. Current Opinion in Oncology, 13, 101-109. http://dx.doi.org/10.1097/00001622-200103000-00004

[28] Valagussa, P. (2001) HER2 Status: A Statistician's View. Annals of Oncology, 12, S29-S34. http://dx.doi.org/10.1093/annonc/12.suppl 1.S29

[29] Scata, K.A. and El-Deiry, W.S. (2007) P53, BRCA1 and Breast Cancer Chemoresistance. Advances in Experimental Medicine and Biology, 608, 70-86. http://dx.doi.org/10.1007/978-0-387-74039-3_5 
[30] Dawood, S. (2010) Triple-Negative Breast Cancer: Epidemiology and Management Options. Drugs, 70, 2247-2258. http://dx.doi.org/10.2165/11538150-000000000-00000

[31] Yasui, W. (2005) Molecular-Pathological Diagnosis of Gastric Cancer. Gan to Kagaku Ryoho, 32, 427-431.

[32] Yashi, W., Oue, N., Ito, R., Kuraoka, K. and Nakayama, H. (2004) Search for New Biomarkers of Gastric Cancer through Serial Analysis of Gene Expression and in Its Clinical Implications. Cancer Science, 95, 385-392. http://dx.doi.org/10.1111/j.1349-7006.2004.tb03220.x

[33] Sellheyer, K. and Belbin, T.J. (2004) DNA Microarrays from Structural Genomics to Functional Genomics: The Applications of Gene Chips in Dermatology and Dermatopathology. Journal of the American Academy of Dermatology, 51, 681-692. http://dx.doi.org/10.1016/j.jaad.2004.03.038

[34] Capurso, G., Festa, S., Valente, R., Piciucchi, M., Panzuto, F., Jensen, R.T., et al. (2012) Molecular Pathology and Genetics of Pancreatic Endocrine Tumors. Journal of Molecular Endocrinology, 49, R37-R50.

[35] Almadori, G., Bussu, F. and Paludetti, G. (2008) Should There Be More Molecular Staging of Head and Neck Cancer to Improve the Choice of Treatments and Thereby Improve Survive? Current Opinion in Otolaryngology \& Head \& Neck Surgery, 16, 117-126. http://dx.doi.org/10.1097/MOO.0b013e3282f6a4b0

[36] Godley, L.A., Cunningham, J., Cunningham, J., Dolan, M.E., Huang, R.S., Gurbuxani, S., McNerney, M.E., et al. (2011) An Integrated Genomic Approach to the Assessment and Treatment of Acute Myeloid Leukemia. Seminars in Oncology, 38, 215-224. http://dx.doi.org/10.1053/j.seminoncol.2011.01.003

[37] Tian, C., Markman, M., Zaino, R., Ozols, R.F., McGuire, W.P., Muggia, F.M., et al. (2009) CA-125 Change after Chemotherapy in Prediction of Treatment Outcome among Advanced Mucinous and Clear Cell Epithelial Ovarian Cancers: A Gynecologic Oncology Group Study. Cancer, 115, 1395-1403. http://dx.doi.org/10.1002/cncr.24152

[38] Ludwig, J.A. (2008) Personalized Therapy of Sarcomas: Integration of Biomarkers for Improved Diagnosis, Prognosis, and Therapy Selection. Current Oncology Reports, 10, 329-337. http://dx.doi.org/10.1007/s11912-008-0051-6

[39] Auman, J.T., McLeod, H.L. and Akiyama, S. (2008) Cancer Pharmacogenomics, DNA Genotyping and Gene Expression Profiling to Identify Molecular Determinants of Chemosensitivity. Drug Metabolism Reviews, 40, 303-315. http://dx.doi.org/10.1080/03602530801952427

[40] Huang, Y. and Sadée, W. (2003) Drug Sensitivity and Resistance Genes in Cancer Chemotherapy: A Chemogenomics Approach. Drug Discovery Today, 8, 356-363. http://dx.doi.org/10.1016/S1359-6446(03)02654-0

[41] Quintieri, L., Fantin, M. and Vizier, C. (2007) Identification of Molecular Determinants of Tumor Sensitivity and Resistance to Anticancer Drugs. Advances in Experimental Medicine and Biology, 593, 95-104. http://dx.doi.org/10.1007/978-0-387-39978-2_10

[42] Lehne, G. (2000) P-Glycoprotein as a Drug Target in the Treatment of Multidrug Resistant Cancer. Current Drug Targets, 1, 85-99. http://dx.doi.org/10.2174/1389450003349443

[43] Zhang, J.T. (2007) Use of Arrays to Investigate the Contribution of ATP-Binding Cassette Transporters to Drug Resistance in Cancer Chemotherapy and Prediction of Chemosensitivity. Cell Research, 17, 311-323. http://dx.doi.org/10.1038/cr.2007.15

[44] Conseil, G., Deeley, R.G. and Cole, S.P. (2005) Polymorphisms of MRP1 (ABCC1) and Related ATP-Dependent Drug Transporters. Pharmacogenetics and Genomics, 15, 523-533.

[45] Lønning, P.E. (2010) Molecular Basis for Therapy Resistance. Molecular Oncology, 4, 284-300. http://dx.doi.org/10.1016/j.molonc.2010.04.005

[46] Kubota, T. (2000) Recent Advance in Gastric Cancer Chemotherapy. Gan to Kagaku Ryoho, 27, 2043-2047.

[47] Volpato, M. and Phillips, R.M. (2007) Tailoring Targeted Therapy to Individual Patients: Lessons to Be Learnt from the Development of Mitomycin C. Cancer Genomics \& Proteomics, 4, 175-186.

[48] Bachrach, U. and Wang, Y. (2003) In Vitro Chemosensitivity Testing of Hematological Cancer Patients: Detection of Ornithire Decarboxylase. Recent Results in Cancer Research, 161, 62-70.

[49] Sita-Lumsden, A., Dart, D.A., Waxman, J. and Bevan, C.L. (2013) Circulating MicroRNAs as Potential New Biomarkers for Prostate Cancer. British Journal of Cancer, 108, 1925-1930. http://dx.doi.org/10.1038/bjc.2013.192

[50] Peña-Llopis, S., Christie, A., Xie, X.J. and Brugarolas, J. (2013) Cooperation and Antagonism among Cancer Genes: The Renal Cancer Paradigm. Cancer Research, 73, 4173-4179. http://dx.doi.org/10.1158/0008-5472.CAN-13-0360

[51] Thomas, B.H., Kjems, J. and Damgaard, C.K. (2013) Circular RNA and miR7 in Cancer. Cancer Research, 73, 56095612.

[52] Klaus, P. and Catherine, A.P. (2013) Real-Time Liquid Biopsy in Cancer Patients: Fact or Fiction? Cancer Research, 73, 6384-3688. http://dx.doi.org/10.1158/0008-5472.CAN-13-2030

[53] Sato, H., Tsubosa, Y. and Kawano, T. (2012) Correlation between the Pretherapeutic Neutrophil to Lymphocyte Ratio 
and the Pathologic Response to Neoadjuvant Chemotherapy in Patients with Advanced Esophageal Cancer. World Journal of Surgery, 36, 617-622. http://dx.doi.org/10.1007/s00268-011-1411-1

[54] Weber, W.A. (2006) Position Emission Tomography as an Imaging Biomarker. Journal of Clinical Oncology, 24, 3282-3292. http://dx.doi.org/10.1200/JCO.2006.06.6068

[55] Herrmann, K., Krause, B.J., Bundschuh, R.A., Dechow, T. and Schwaiger, M. (2009) Monitoring Response to Therapeutic Interventions in Patients with Cancer. Seminars in Nuclear Medicine, 39, 210-232. http://dx.doi.org/10.1053/j.semnuclmed.2008.12.001

[56] Krishan, A. and Arya, P. (2002) Monitoring of Cellular Resistance to Cancer Chemotherapy. Hematology/Oncology Clinics of North America, 16, 357-372. http://dx.doi.org/10.1016/S0889-8588(01)00016-8

[57] Katayanagi, N., Suzuki, T., Tanaka, O. and Muto, T. (1992) Flow Cytometric BrdU/DNA Assay for Anticancer Agent Sensitivity Test. Nihon Rinsho, 50, 2386-2390.

[58] Hoffman, R. (1992) Histoculture and the Immunodeficient Mouse Come to the Cancer Clinic-Rational Approches to Individualizing Cancer-Therapy and New Drug-Evaluation. International Journal of Oncology, 1, 467-474.

[59] Maenpaa, J., et al. (1988) The Subrenal Capsule Assay for Chemosensitivity Testing of Tumors. A Review. Zentralbl Gynakol, 110, 989-996.

[60] Lazaridis, G., Pentheroudakis, G. and Pavlidis, N. (2008) Integrating Trastuzumab in the Neoadjuvant Treatment of Primary Breast Cancer: Accumulating Evidence of Efficacy, Synergy and Safety. Critical Reviews in Oncology/Hematology, 66, 31-41. http://dx.doi.org/10.1016/j.critrevonc.2007.07.002 